
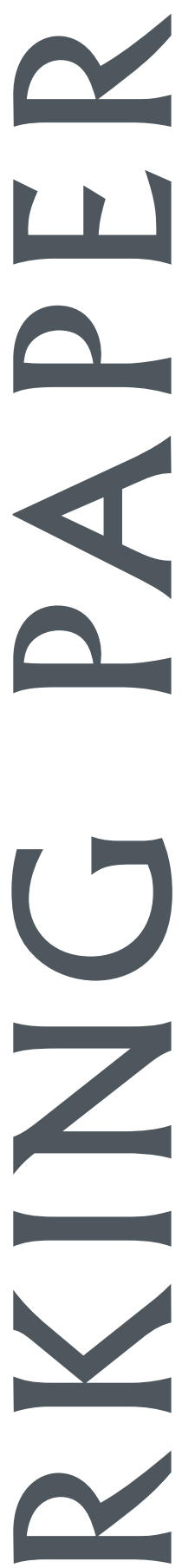

EAST-WEST CENTER 
The U.S. Congress established the East-West Center in 1960 to foster mutual understanding and cooperation among the governments and peoples of the Asia Pacific region including the United States. Funding for the Center comes from the U.S. government with additional support provided by private agencies, individuals, corporations, and Asian and Pacific governments.

East-West Center Working Papers are circulated for comment and to inform interested colleagues about work in progress at the Center.

For more information about the Center or to order publications, contact:

Publication Sales Office

East-West Center

1601 East-West Road

Honolulu, Hawaii 96848-1601

Telephone: 808-944-7145

Facsimile: 808-944-7376

Email: ewcbooks@EastWestCenter.org

Website: www.EastWestCenter.org 


\section{Economics Series}

No. 79, May 2005

\section{How Inefficient are Small-Scale Rice Farmers in Eastern India Really?: Examining the Effects of Microtopography on Technical Efficiency Estimates}

\author{
Nobuhiko Fuwa, Christopher Edmonds, and \\ Pabitra Banik
}

Nobuhiko Fuwa is an International Research Fellow at the International Rice Research Institute in Los Baños, Philippines, and an Associate Professor of Agricultural Economics at Chiba University in Chiba, Japan.

Christopher Edmonds is a Fellow in the Research Program at the East-West Center in Honolulu and was formerly an Affiliate Scientist at the International Rice Research Institute.

Pabitra Banik is an Agronomist and Associate Professor at Agricultural Science Unit in the Biological Sciences Division of the Indian Statistical Institute in Kolkata, India.

The input and support of Suan Pheng Kam and research assistance by Lorena Villano in earlier phases of this research are gratefully acknowledged.

Copyright 2005 by Nobuhiko Fuwa, Christopher Edmonds, and Pabitra Banik. All rights reserved. Readers may make verbatim copies of this document for noncommercial purposes by any means, provided that this copyright notice appears on such copies.

East-West Center Working Papers: Economics Series is an unreviewed and unedited prepublication series reporting on research in progress. The views expressed are those of the author and not necessarily those of the Center. Please direct orders and requests to the East-West Center's Publication Sales Office. The price for Working Papers is $\$ 3.00$ each plus shipping and handling. 


\title{
How inefficient are small-scale rice farmers in eastern India really? Examining the effects of microtopography on technical efficiency estimates
}

\author{
Nobuhiko Fuwa*, Christopher Edmonds, and Pabitra Banik ${ }^{*}$
}

May 2005

\section{Selected Paper prepared for presentation at the American Agricultural Economics Association Annual Meeting, Providence, Rhode Island, July 24-27, 2005}

\begin{abstract}
We focus on the impact of failing to control for differences in land types defined along toposequence on estimates of farm technical efficiency for small-scale rice farms in eastern India. In contrast with the existing literature, we find that those farms may be considerably more technically efficient than they appear from more aggregated analysis without such control. Farms planted with modern rice varieties are technically efficient. Furthermore, farms planted with traditional rice varieties operate close to the production frontier on less productive lands (upland and mid-upland), but significant technical inefficiency exists on more productive lands (medium land and lowland).
\end{abstract}

JEL Classification: O13, O33, Q12, Q16

Key words: technical efficiency; stochastic frontier production function; productivity; rice; India

Copyright 2005 by Nobuhiko Fuwa, Christopher Edmonds, and Pabitra Banik. All rights reserved. Readers may make verbatim copies of this document for non-commercial purposes by any means, provided that this copyright notice appears on such copies.

\footnotetext{
* Contact author: Nobuhiko Fuwa, Agricultural Economics, Chiba University, 648 Matsudo, Matsudo-City, Chiba. 271-8510 Japan. Phone/fax: 81-47-308-8932, email: nfuwa@faculty.chiba-u.jp.

"Nobuhiko Fuwa is an International Research Fellow at the International Rice Research Institute in Los Baños, Philippines, and an Associate Professor of Agricultural Economics at Chiba University in Chiba, Japan. Christopher Edmonds is a Fellow in the Research Program at the East-West Center in Honolulu and was formerly an Affiliate Scientist at the International Rice Research Institute. Pabitra Banik is an Agronomist and Associate Professor at Agricultural Science Unit in the Biological Sciences Division of the Indian Statistical Institute in Kolkata, India. The input and support of Suan Pheng Kam and research assistance by Lorena Villano in earlier phases of this research are gratefully acknowledged.
} 


\section{Introduction}

The diffusion and adoption of green revolution technologies for wheat and rice has been slow in two extensive agricultural regions in India: the dry semi-arid tropics and the eastern India's rice-growing region (Walker and Ryan). While the understanding of the causes of slow adoption in the former area is relatively well understood due in large part to the International Crop Research Institute for Semi-Arid Tropics's (ICRISAT) intensive village-level studies, relatively less research has been carried out on the latter area. This article focuses on the selected areas of the Chhotanagpur Plateau in eastern India, an area characterized by its high poverty incidence and large share of 'tribal' households, low productivity in the regions largely rain-fed based agriculture, and an environmentally degraded landscape characterized by undulating topography.

The main policy question underlying this article is: what should investment priorities be for efforts to improve the agricultural productivity-and through this the living standards of impoverished households in eastern India that derive a significant share of their income from small farms? We address this question by estimating the degree of technical efficiency of these farms. A finding that there is substantial technical inefficiency would suggest directing public investments toward measures for improving technical efficiency (typically through farmer education, agricultural extension, land tenure reforms, infrastructure development, etc) would be expected to yield high shortterm payoffs. On the other hand, if these small farm households are found to be 'poor but (technically) efficient,' à la T. W. Schultz, then public investments should be directed to research and development for new technologies. This question is currently of particular 
policy importance as India's policymakers redouble rural development efforts in the country following the 2004 national elections. A number of analysts have argued the strong support of the rural poor-frustrated by the slow pace of improvements in living standards despite stronger growth in the overall Indian economy-contributed to the unexpected victory of the coalition led by the Congress party.

In order to address this question, we follow the conventional approach of measuring small farm efficiency by estimating stochastic frontier production functions. In our application of this technique, we focus on the methodological issue of possible effects on estimation results, and through these the policy conclusions, of controlling for the effect of environmental conditions on farm efficiency. A large literature estimating technical efficiency in farm production in India and elsewhere has generally found significant technical inefficiency among farmers (e. g., Audibert, Kalirajan 1981, 1982, also see Battese 1992, for a survey). ${ }^{1}$ However, Sherlund, Barret and Adesina have recently shown that failure to control for the effect of differences in the environmental characteristics of farm (e.g., climate, soil type and quality, and pests infestation) can lead to significant overestimation of the degree of technical inefficiency. ${ }^{2}$ Sharing a similar methodological concern for the effect of subtle differences in such characteristicsdriven by concern about the particular natural environment of our study area in eastern India - we examine estimates of technical inefficiency with and without disaggregation in terms of farm plot location on the microtopography that typifies the land situation in the

\footnotetext{
${ }^{1}$ Bagi (1982) and Battese and Coelli (1992), on the other hand, represent a minority of studies finding relatively high technical efficiency of farmers in India.

2 Coelli, Perelman and Romano apply a more general approach, but report similar results, in their analysis of the international airline industry.
} 
study area. Lack of proper control for various dimensions of farm heterogeneity has the potential to alter findings regarding farm inefficiency, and through this, policy conclusions regarding the appropriate focus in rural development efforts in rural eastern India.

The article's analysis of farm production and productive efficiency proceeds at several levels of aggregation. Starting with the household-aggregate level analysis and moving to plot-level analysis enables more detailed data regarding the environmental conditions to be accounted for in the estimates. Environmental variables treated include the availability of irrigation water and land location on a low scale toposequence. We examine how disaggregation and consideration of additional control influence estimation results and inferences about the extent of technical efficiency among small farmers in our survey sample. As expected, results suggest that ignoring differences in the topographical position of farm plots holds serious consequences for technical efficiency estimates.

The rest of the article is organized as follows. Section 2 briefly discusses some of the major characteristics of the poor rice farmers in our survey in eastern India. Section 3 outlines our empirical strategy for conducting sensitivity analysis and introduces our empirical model. Section 4 presents estimation results. Section 5 considers possible policy implications of findings and concludes the article with some final observations. 


\section{Characteristics of the study area and data set $^{3}$}

Following the policy reforms of the early 1990s, the Indian economy has displayed renewed dynamic in terms of its growth and achievements in poverty reduction.

However, recent research has shown that not all regions of the country have benefited from this improved economic performance and large variation exists within India in terms of the rate of income growth and extent of poverty reduction successes (e. g., Datt and Ravallion). This follows an earlier post-War history in the country in which green revolution technologies for wheat and rice cultivation enabled marked increases in agricultural productivity and aggregated food production in most agricultural regions of the country in the 1970s and 1980s, but bypassed — at least initially_two of the country's extensive agricultural regions: the semi-arid tropics and eastern India's rainfed ricegrowing region (Walker and Ryan). Thanks to the intensive village level studies and longitudinal household surveys carried out by the International Crop Research Institute for Semi Arid Tropics, our knowledge of the former area is substantial and rich. In contrast, the eastern rainfed rice region has been the subject of relatively little quantitative analysis and much less is known about the agricultural practices and farm efficiency in this region.

Our study area lies on the Chhotanagpur Plateau, and is part of the so-called "tribal belt" in eastern India. The data analyzed in this study was collected jointly by International Rice Research Institute (IRRI) and Indian Statistical Institute (ISI) in 1998 and 1999. The survey sample covered two neighboring districts in the states of

\footnotetext{
${ }^{3}$ This section draws heavily on Banik et al.
} 
Jharkhand (a part of Bihar state prior to 2000) and West Bengal. A total of 541 households were selected for interviewing based on a stratified random sample of households in 8 villages in Giridih district (Jharkhand) and 8 villages in Purulia district (West Bengal). In each village, 35 households were randomly selected from Census lists across 5 landholding groups including landless households. The survey questionnaire captured a host of economic and agricultural characteristics of the households and their farms, but was particularly focused on capturing information on agricultural production activities at the plot level. Our empirical analysis utilizes rice production data from 1089 plot-level observations (operated by 469 farm households) during the Kharif season (i.e., the monsoon season spanning roughly between June and November/December). Table 2 presents sample averages and variances for the key variables used in the production estimates.

The incidence of poverty among rural households in the area has been estimated to be among the highest in India and perhaps in all of Asia. Statewide headcount poverty ratios in Bihar (which included Giridih District prior to 2000) and West Bengal (where Purulia district lies) were the second and third highest in 1987-88 and second and fifth highest in 1999 (Deaton). Based on the Planning Commission's official poverty line for $1999,60 \%$ of sampled households were poor. Indicators of social development and basic need satisfaction also suggest that the study area is poor. For example, the average years of schooling of the household heads was only 3.6 years. 
Agriculture in the area is largely rice-based and features a very strong subsistence orientation. ${ }^{4}$ The average size of the farm operated by our sample households was 2.2 acres. The majority of our sample farms relied on traditional cultivation technique in their rice production in the late 1990s. The rate of adoption of modern rice varieties (MVs) remained relatively low (see below), and the use of agricultural machinery, such as tractors and power tillers, was almost nonexistent among the sample farmers.

One significant feature of the agricultural production environment in the study area is the combination of the area's undulating topography and highly dissected landscape. These characteristics give rise to low scale variations in terrain and soil and water conditions that influence the kinds of crops that can be grown, the time windows for cropping, and feasible cropping systems across land lying at different levels of the toposequence. Local farmers typically distinguish four different levels according to their perception of the soil moisture gradient along the toposequence: upland, mid-upland, medium land and lowland. Going from the upland plots to the lowland plots, agricultural experts from the ISI have observed a generally consistent trend of increasing soil fertility. Table 1 summarizes the results of sample soil chemical analysis conducted in one of our sample villages showing the systematic pattern of increasing chemical nutrients contained in the soil along typosequence. ${ }^{5}$ One of the most striking characteristics of these land types is that the relatively minor differences in elevation define different land types. The difference in elevation between adjacent plots along the toposequence is typically small ( 3 to 5 meters), meaning very minor differences in elevation are associated with

\footnotetext{
${ }_{5}^{4}$ For example, only $21 \%$ of the sample households reported selling of rice during the survey year.

${ }^{5}$ At the same time, however, lowlands sometimes suffer from excessive water.
} 
significant changes in plot characteristics (e.g., moisture and nutrient holding capacity, vulnerability to erosion).

Farmers have adapted to these microtopographies by adjusting cropping patterns (i.e., particular rice varieties cultivated) and crop management practices. Upland plots are typically planted with short duration (85-90 days), draught-tolerant, and low-yielding traditional/rustic rice varieties or traditional minor millets. Mid-upland plots are typically planted with medium-duration rice varieties. On medium land, where soil moisture is available for a longer period than on the higher terraces, long-duration traditional rice varieties were most widely planted. At the bottom of toposequence-on lowland plotsfarms typically planted traditional long-duration varieties with low inputs of manure. While planting of traditional varieties predominated according to survey responses, $\mathrm{MV}$ rice is cultivated mainly on medium land and lowland plots, although the rate of adoption remains relatively low. The share of land areas planted with modern varieties ranged from $6 \%$ on upland to $21 \%$ on lowland and $24 \%$ on medium land.

Corresponding to the importance of plot position on the terrace, average paddy yields observed among our sample plots increased as one moves down the toposequence from upland to lowland. On uplands, rice yields averaged 2.1 tons per hectare as compared to an average yield of 3.3 tons per hectare on lowland. Refer to Table 2 for complete descriptive statistics regarding rice cultivation on surveyed farms and on plots of the different land types. Both summary statistics and the stylized facts observed from detailed fieldwork in the study suggest that disaggregation across plots along 
toposequence, and controlling differences in other environmental conditions, can exert large influence on estimates of farm technical efficiency.

\section{Methodology for testing sensitivity of technical efficiency estimates}

We examine technical efficiency of small farmers in eastern India by estimating stochastic frontier production functions (SFPFs), as pioneered by Aigner, Lovell and Shmidt and Meeusen and van den Broeck. In particular, the analysis seeks to evaluate how including details about the microtopographic position and other environmental characteristics of farm plots affects inferences that can be made regarding small farmer technical efficiency. To do this, we estimate SFPFs at different levels of land aggregation and including different controls variables and compare estimation results. SFPFs estimation models take the general form:

$$
\ln Y_{i}=f\left(X_{i}, Z_{i} ; \beta\right)+V_{i}-U_{i}
$$

where $\mathrm{f}($.$) defines the production frontier with i$ representing $i^{\text {th }}$ observation (either plotlevel or farm level, as detailed below). $\mathrm{Y}_{\mathrm{i}}$ is the total amount (in kilograms) of paddy produced, $X_{i}$ is a vector of production inputs (land, seed, labor, and fertilizer), $Z_{i}$ is a vector of additional environmental variables (e.g., irrigation, village dummies), and $\beta$ is the vector of unknown estimation parameters that characterize the production frontier. Because most environmental characteristics are homogeneous across farms in a single village, $Z_{i}$ are measured at the village, and capture access to infrastructure and other institutional variations as well as environmental characteristics. $V_{i}$ represents random error (e. g., measurement error) and is assumed to be normally distributed with mean zero and variance $\sigma_{v}^{2}$, while $U i(\geq 0)$ captures the non-negative component of the estimation 
residual and is interpreted as representing technical inefficiency. By partitioning the error term into a normally distributed component and an asymmetric component, SPFP estimation attributes the first component to model measurement error and the latter to systematic differences across observations that relate to differences in the productive efficiency of sample farms and farm plots.

It is standard practice in SFPF estimation for the production frontier $f($.$) to be$ parameterized as a Translog or Cobb-Douglas functional form. The Translog specification is more attractive because of its greater flexibility and fewer a priori restrictions (e.g., assumptions regarding the substitution elasticity across inputs), but its application comes at the cost of reduced degrees of freedom and greater likelihood of encountering problems of collinearity among regressors. In this article, we initially estimate (1) as a Translog production frontier taking the form:

$$
\ln Y_{i}=\beta_{0}+\sum_{k=1}^{K} \beta_{k} \ln X_{k i}+1 / 2 \sum_{j=1}^{K} \sum_{k=1}^{K} \beta_{j k} \ln X_{j i} \ln X_{k i}+\sum_{m=1}^{M} \beta_{m} Z_{m i}+V_{i}-U_{i}, \text { (2) }
$$

with $\beta_{\mathrm{jk}}=\beta_{\mathrm{kj}}(k=0,1, \ldots, K)$. We then test whether Cobb-Douglas is an adequate specification by testing the joint significance of $\mathrm{H}_{0}: \beta_{j k}=0$ for all $j, k=1, \ldots, K$. When the null hypothesis is not rejected, we re-estimate the production frontier using a CobbDouglas specification. ${ }^{6}$ If the null hypothesis is rejected, we retain the Translog specification.

A variety of distributions (e.g., exponential, half-normal, two-parameter gamma, or truncated normal) are used to characterize the technical inefficiency term $U_{i}$ in the

\footnotetext{
${ }^{6}$ The equation estimated in this case takes the form: $\ln Y_{i}=\beta_{0}+\sum_{k=1}^{K} \beta_{k} \ln X_{k i}+\sum_{m=1}^{M} \beta_{m} Z_{m i}+V_{i}-U_{i}$.
} 
existing literature applying the SPFP approach. ${ }^{7}$ While distributions that involve twoparameters (e.g., two parameter gamma, truncated normal) can accommodate a wider range of possible distributional shapes, their application appears to come at a potential cost of increased difficulty in the identification of parameters (see Ritter and Simar). In addition, the empirical significance of applying different distributional assumptions for $U_{i}$ has not been clearly established in the existing literature. For example, earlier research has shown that while the quantitative magnitudes of predicted firm-level technical efficiency are sensitive to such distributional assumptions, the ranking among observations based estimated technical efficiency is not (Kumbhakar and Lovell). Given the state of our knowledge, we initially experimented with alternative distributional assumptions of exponential, half-normal and truncated normal, but found that model identification was indeed difficult when the truncated normal distribution was used. The estimated mean of $U_{i}$ had relatively large standard errors and was not significantly different from zero. Furthermore, we find that qualitative results of estimates are largely invariant with respect to the distributional assumption for $U_{i}$, as will be discussed in the next section. Consequently, in our estimates we apply the assumption that $U_{i}$ is distributed as a half-normal distribution (a relatively simpler distribution and that has been widely used) with variance $\sigma_{u}^{2 .} .8$ This treatment follows the suggestion of Ritter and Simar (p. 181), and Kumbhakar and Lovell (p. 90)

\footnotetext{
${ }^{7}$ See Kumbhkar, Lovell 2000 for a more comprehensive discussion of alternative distributional assumptions found in the literature.

${ }^{8}$ Empirical results calculated applying other distributional assumptions are available from the authors upon request.
} 
We test for the presence of statistically significant technical inefficiency among survey farmers by examining the null hypothesis $\mathrm{H}_{0}: \sigma_{\mathrm{u}}{ }^{2}=0$ against the alternative hypothesis $H_{1}: \sigma_{u}^{2}>0$. As shown by Coelli (1995), a one-sided generalized likelihood test statistic is asymptotically distributed as a mixture of chi-square distributions with one degree of freedom (see also Kumbhakar and Lovell and Coelli, Rao and Battese). We predict technical efficiency scores for individual plots as $T E_{i}=\exp \left(-U_{i}\right)$, conditional on the observed composite error $\left(V_{i}-U_{i}\right)$, which follows the approach developed by Jondrow et al. and Battese and Coelli (1988).

The principal methodological question we seek to address in this article is: what is the effect of including (or failing to include) detail concerning the microtopography of farm plots on the estimation of plot-level technical efficiency. Starting from the farmwide level of analysis and moving to plot-level analysis, and adding more variables in the estimates to account for other environmental conditions explicitly, we examine how the disaggregation and additional controls influence inferences about the extent of technical efficiency of small farmers. More specifically, we estimate production frontiers at 3 levels of aggregation:

1. Farm (household) level where the output and inputs of all the plots are aggregated,

2. Plot level analysis where plots of different land types (topographical positions) are pooled together, and

3. Plot level analysis for each of the four land types across the toposequence. 
In addition, at each level of the analysis we estimate two alternative specifications. One specification defines production as depending upon only the level of production inputs (i.e., land area, labor, fertilizer and seed). The second specification adds additional control variables to capture the effect of irrigation availability (a dummy variable taking the value one if the plot is irrigated and zero otherwise) and village-level dummies on farm/plot output. In addition, in the plot level analyses (i. e., pooled plot level as well as separate analyses by land type ${ }^{9}$ ) separate estimates are carried out for plots in which modern and traditional rice varieties were cultivated.

\section{Estimation results}

In all but one case, the estimated quadratic terms of the Translog production functions are statistically significant, so the Translog speciation is retained for those cases. In the case of separate estimation of 'medium-land,' the quadratic terms were jointly not significantly different from zero, so we used Cobb-Douglas form for those estimates. All the models were statistically significant (with a 95 percent or higher probability) according to the Wald chi-square tests.

\section{Estimated Production Frontier Parameters}

Tables 3 and 4 summarize the mean and standard deviation of the estimated (plotspecific) input elasticity of output based on our estimated production frontier under the various specifications detailed on the table. In general, estimation results suggest land is the most important productive input in terms of input elasticity, followed by seed. The relatively small (and occasionally negative) elasticity of labor is somewhat puzzling, but

\footnotetext{
${ }^{9}$ Plot-specific estimates disaggregated by land type could not be carried out for plots planted with modern varieties because the number of observations was inadequate for such analyses.
} 
is consistent with previous findings from rice farmers in Bangladesh (Sharif and Dar) and wheat farmers in Pakistan (Battese and Broca). A plausible explanation for the negative coefficients estimated for labor input in some of the specifications relates to the fact that labor input is pre-determined to a much lesser extent than other inputs (i.e., decisions regarding the size of plot to cultivate and the amount of seed to apply much be made at the start of the planting season) and increased application of labor is a common response to crop management problems (e.g., drought, or weed/insect infestations).

We find that the estimated input elasticities tend to vary significantly across different land types. Elasticities also varied — although on a less consistent basisdepending upon inclusion of additional control variables (i.e., irrigation availability and village dummies) in the estimation. The mean elasticity of output with respect to land input, for example, ranges widely between 0.3 on uplands (based on the model without irrigation or village controls) and 0.86 on medium land (based on the model without irrigation or village controls). This suggests that the estimated technology parameters that characterize production frontiers are sensitive to the position of the land in the local microtopography. This is not surprising, however, given the fact that the farms plants different rice varieties and apply inputs at different levels and timings across different land types. These findings are in line with Sherlund, Barrett and Adesina's general conclusions. Having established the overall validity of the SFPF estimates, we next turn our attention to the principal point of interest in carrying out the estimates - the models' estimates of farm technical efficiency. 


\section{Technical efficiency estimates}

We generally find that the estimates of technical efficiency are significantly influenced by disaggregation of farm production across land types and plots. Test results of statistical significance for technical efficiency with various specifications are summarized in Table 5, while the predicted technical efficiency scores are summarized in Table 6. As is typically found in the literature on the farm level estimation of SFPF, our estimation results indicate that there is significant technical inefficiency among the rice farms in our survey. As shown in the first column of Table 5, the null hypothesis that there is no technical inefficiency (i.e., $\sigma_{u}$ equals zero) is strongly rejected (probability value of less than 0.01). Average technical efficiency scores estimated for our sample of farms are between 0.75 (the production frontier specification with production inputs only) and 0.8 (the specification with additional irrigation and village heterogeneity controls).

Individual technical efficiency estimates range between 0.4 and 0.95 , based on the model including additional irrigation and village heterogeneity controls. The first column of Table 6 reports these results. The magnitude of these estimated technical efficiency scores is roughly comparable to those found in the literature on farms in developing country settings (Battese 1992). ${ }^{10}$ However, the analysis at the aggregate farm (household) level analysis does not indicate strong influence of irrigation availability and village-level heterogeneity controls on estimates of technical efficiency, which contrast sharply with the earlier findings of Sherlund, Barrett and Adesina.

\footnotetext{
${ }^{10}$ We should be cautious in interpreting these results, however, in that the comparison of efficiency scores says nothing about the relative efficiency across samples of farmers, as emphasized by Coelli, Rao and Battesse.
} 
When we estimate farm technical efficiency at the more disaggregated plot-level (separately for each toposequence-defined land type) and add more environmental control variables, our inferences regarding farmer technical inefficiency change significantly and more complex pattern emerges. For example, our estimates using the sub-sample of plots planted with MVs fail to reject the null hypothesis that there is no technical inefficiency and the point estimates of the ratio of standard deviations $\lambda\left(=\sigma_{\mathrm{u}} / \sigma_{\mathrm{v}}\right.$ : an indicator of the relative contributions of $\mathrm{u}$ and $\mathrm{v}$ to the composite error term) are close to zero (Table 5, $2^{\text {nd }}$ column). The average predicted value of technical efficiency is close to one. This suggests that rice cultivation using modern rice varieties in eastern India is efficient and operating near the production frontier. This finding sharply contrasts with those of earlier studies, such as Kalilajan (1982) and Sharif and Dar, that found significant inefficiency among rice farms planting MVs. However, these earlier studies covered different years and regions of India, namely, from Tamil Nadu State in the late 1970s and in Bangladesh in the mid-1980s, respectively. One possible interpretation for the different results of our study and the earlier studies is that significant technical inefficiency among farmers present in the early stage of MV introduction has been overcome as Indian farmers have learned and adopted standard practices for obtaining maximum yield with modern rice varieties over the course of the many years since MVs were introduced.

While our estimates suggest that there is not a statistically significant level of technical inefficiency on rice plots planted with MVs, the equivalent analysis (i.e., pooled plot-level analysis containing all land types) for rice plots planted with traditional varieties (TVs) indicates that there is significant technical inefficiency in TV rice 
production (i.e., the null hypothesis of 'no technical inefficiency' is strongly rejected). The predicted technical efficiency scores range from 0.75 to 0.79 , as shown in the third column of Table 5 and Table 6 . However, when plot-level estimates are carried out separately for plots of each land type, we obtain highly statistically significant technical inefficiency parameters in the estimates for medium land or lowlands plots, but not for upland and mid-upland plots. For medium land and lowland plot estimates, the composite error term $\left(V_{i}-U_{i}\right)$ is dominated by the technical inefficiency term $\left(U_{i}\right)$. The model that includes dummy variables indicating the availability of irrigation on the plot and village effects, point estimates of $\lambda\left(=\sigma_{\mathrm{u}} / \sigma_{\mathrm{v}}\right)$ are 2.5 on lowland plots and 3.4 on medium land. In the case of upland and mid-upland, the null hypothesis of no technical efficiency is still rejected in the model that does not include the additional control variables (the 'minimum' specification using regular production inputs only—land, seed, fertilizer, labor), however, once the irrigation and village dummy variables are introduced, the null hypothesis is no longer rejected. Correspondingly, with the additional environmental controls, the point estimates of $\lambda$ become very small (less than 0.1 ), although they are not estimated very precisely. From these results, it is clear that model estimates are somewhat sensitive to changes in the set of control variables introducing additional environmental control variables. In the case of upland and mid-upland rice plots planted with traditional varieties, adding indicators of irrigation availability or village level heterogeneity appears to have a major influence on the inferences that can be made regarding the existence of technical efficiency. This finding is in line with that of Sherlund, Barrett and Adesina. In contrast, however, in the case of traditional rice plots 
on medium land and lowland, the introduction of additional environmental controls does not significantly influence inferences regarding technical efficiency.

A similar picture also emerges from review of the estimated mean technical efficiency scores shown in Table 6. The mean technical efficiency scores are in the range between 0.7 and 0.8 on medium land and low land. These results are consistent with findings of earlier research showing significant inefficiency in developing country agriculture. On the other hand, however, the mean inefficiency scores (based on the model with irrigation and village heterogeneity controls) are close to one in the case of upland and mid-upland.

To summarize, we find that technical inefficiency is prevalent among the most fertile plots lying in the lower portions along toposequence (i.e., medium-land and lowland) while systematic technical inefficiency is not present on plots in the often degraded less favorable upper portions of the terrace toposequence (upland and midupland) or on plots planted with modern rice varieties — which are predominantly (68 percent) cultivated on medium land and lowland plots. This suggests that the cultivation practices of rice farms in the study area in eastern India are more technically efficient on the least favorable (upland and mid-upland plots) and the most favorable (lands on lower terraces planted with MVs). Rather surprisingly, technical efficiency is most evident on medium land and lowland plots (relatively favorable plots in terms of their moisture availability) planted with TVs (the varieties of rice traditionally cultivated in the study area so the crop farmers in the area should be most accustomed to). A practical implication of this result is that there is the potential to improve the technical efficiency 
of some farmers in their cultivation of relatively more favorable land parcels. Our results also suggest the encouraging finding that adoption of MVs of rice is accompanied by an understanding of proper cultivation practice for these varieties.

A possible explanation of these results relates to the greater variability of soil characteristics found in upland and mid-upland plots. The water holding capacity and soil nutrient composition of upland and mid-upland plots appear to be relatively more heterogeneous, while medium land and lowland plots exhibit less variability in their moisture holding capacity and soil nutrients. The superior nutrient composition of plots on lower terraces of the toposequence is documented in Table 1, but the soil samples analyzed also established the greater heterogeneity of nutrient characteristics of upland and mid-upland plots. In addition, the tendency for nutrients to be carried off plots on higher portions of the toposequence - particularly during heavy monsoon rains — and to be transferred to lower terraces depends upon idiosyncratic characteristics of the local topography, which is heterogeneous. This run-off of nutrients also tends to increase the homogeneity of medium land and lowland plots.

As a result of the more heterogeneous and less favorable agricultural conditions encountered on higher terraces, the amount of production farms can garner from rice cultivated on upland and mid-upland plots is more uncertain and depends more on luck than lower terrace plots. This is consistent with estimation results that the composite asymmetric error term is dominated by the symmetric random (non-systematic) error (i.e., small $\lambda$ ) in our estimates carried for medium land and lowland plots. Along the lower portions of toposequence, water-holding capacity and nutrient characteristics of the soil is 
relatively more homogeneous (and stable over time), so farm cultivation practices exert relatively more influence over the amount of rice harvested at season's end. As a consequence, variation in farm management skills rather than random shocks have a larger impact on the amount of production (i.e., larger $\lambda$ ).

Our SFPF estimation results for plots upon which MVs were cultivated further suggest that cultivation practices for MV of rice tend to be more uniform across surveyed farms. As shown on Table 2, on average across surveyed farms reported cultivation of MVs of rice, yields are higher and input levels less variant across farms than levels on TV rice plots. This could result from technical extension regarding crop management for MV rice, which leads farms to adopt common techniques in cultivating MV rice plots, although our data do not include information on this aspect.

This finding contradicts established understanding from the existing literature, which finds that technical inefficiency is widespread among farms in developing agriculture. Our findings based on disaggregated analyses at the plot-level suggest that the poor rice farmers in eastern India display differing levels of technical inefficiency depending upon the particular characteristics of their farm plots. Controlling for lowscale differences in plot fertility and moisture holding capacity and other local environmental characteristics causes farms to appear to be considerably more technically efficient than they appear based on aggregated SFPF estimates that fail to take explicit account of production effects of microtopography, irrigation availability, and village level characteristics. 


\section{Conclusions: policy implications and additional considerations}

Existing studies applying SFPF estimation to examine technical efficiency of farmers in developing agricultural regions have found widespread evidence of farm inefficiency. In contrast, our findings that examine technical efficiency at the disaggregated plot-level suggest that the poor rice farming households in eastern India display varying levels of technical efficiency depending upon the particular characteristics of the plot being cultivated. Rather than being uniformly inefficient in farming, farms appear to be efficient in the cultivation of some plots and inefficient in others. To understand why this is the case, it is vital that one understands the local environment and distinct cultivation practices (and to a lesser extent, technology) applied in rice cultivation on plots of different land types. Overall, our results suggest farms are considerably more technically efficient than they may first appear. Farm wide analysis appear to incorrectly attribute differences in output levels to farm mismanagement when such differences are, in fact, due to small scale variations in soil quality and other environmental characteristics observable only at the plot level.

A number of policy implications can be drawn from this research's findings. The fact that farm cultivation of rice on poorer quality land (i.e., upland and mid-upland plots) is known to be relatively unproductive but did not display technical inefficiency suggests that investments on research and development of new crops and technologies to enhance production possibilities for less favorable lands could yield substantial benefits to farms in eastern India. The finding that MV rice cultivation also fails to display systematic technical inefficiency, combined with survey results that show the higher yields and 
lower average input levels on MV rice plots, suggests that the introduction and adoption of MV of rice in the study area has been successful although the MV adoption level remains quite low. Accordingly, further efforts to expand use of MV of rice seem a useful avenue for enhancing farm efficiency and productivity in rice cultivation.

Although farms were found to be technically efficient in their rice cultivation on upper-terrace plots, there appears to be significant technical inefficiency on the lower portions of the land toposequence (i.e., on medium- and lowland plots). This suggests strong potential for short-term gains from efforts aimed at improving technical efficiency in cultivation of TVs of rice on medium- and low-land situations. Development and diffusion of sound crop management practices for rainfed traditional rice varieties through agricultural research adapted to local circumstances and farmer education focusing on these land types appear promising avenues for improving farm productivity and food security. Lastly, the distinct cultivation practices for rice on parcels of different land types and the disparate production outcomes — and technical efficiency displayedin rice cultivation across plots differentiated by land type suggests that efforts to introduce new crops into the study area should take into consideration the fact that farms have developed complex patterns of rice cultivation across land types. 


\section{References}

Aigner, D. J., C. A. K. Lovell, and P. Shmidt. Formulation and estimation of stochastic frontier production models. Journal of Econometrics 6(1977): 21-37.

Bagi, F.S. Economic efficiency of sharecropping: reply and some further results. Malaysia Economic Review 27(1982):86-95.

Banik, P, C. Edmonds, N. Fuwa, S.P. Kam, L. Villano, and D.K. Bagchi. Natural Resource Endowments, Subsistence Agriculture, and Poverty in the Chhotanagpur Plateau. International Rice Research Institute Discussion Paper Series No. 47. Los Baños, Laguna, Philippines, 2004.

Battese, G. Frontier production functions and technical efficiency: a survey of empirical applications in agricultural economics. Agricultural Economics 7(1992):185-208.

Battese, G. and T. Coelli. Prediction of firm-level technical efficiencies with a generalized frontier production function and panel data. Journal of Econometrics 28(1988):387-399.

Battese, G., and T. Coelli. Frontier production functions, technical efficiency and panel data: with application to paddy farmers in India. Journal of Productivity Analysis 3(1992): 153-169.

Battese, G. and S. Broca. Functional forms of stochastic frontier production functions and models for technical inefficiency effects: a comparative study for wheat farmers in Pakistan. Journal of Productivity Analysis 8(1997): 395-414. 
Binam, J. N., J. Tenye, N. Wandji, G. Nyambi, and M. Akoa. Factors Affecting the Technical Efficiency among Smallholder Farmers in the Slash and Burn Agriculture Zone of Cameroon. Food Policy 29(2004): 531-545.

Coelli, T. Estimators and Hypothesis Tests for a Stochastic Frontier Function: A Monte Carlo Analysis. Journal of Productivity Analysis 6(1995): 247-268.

Coelli, T., S. Perelman, and E. Romano. Accounting for environmental influences in stochastic frontier models: with application to international airlines. Journal of Productivity Analysis 11(1999): 251-273.

Coilli, T., D.S.P. Rao, and G.Battese. An Introduction to Efficiency and Productivity Analysis. Boston: Kluwer Academic Publishers, 1998.

Datt, G. and M. Ravallion. Is India's Economic Growth Leaving the Poor Behind? Journal of Economic Perspectives 16(2002): 89-108.

Deaton, A. Computing prices and poverty rates in India 1999-2000. Research Program in Development Studies. Princeton University. Princeton, N.J., USA, 2001.

Jondrow, J., C.A.K. Lovell, I.S. Materov, and P. Schmidt. On the estimation of technical inefficiency I nthe stochastic frontier production function model. Journal of Econometrics 19(1982): 233-238.

Kalirajan, K. An econometric analysis of yield variability in paddy production. Canadian Journal of Agricultural Economics 29(1981): 283-294 . On measuring yield potential of the high yielding varieties technology at farm level. Journal of Agricultural Economics 33(1982): 227-236. 
Kumbhakar, S., and C.A.K. Lovell. Stochastic Frontier Analysis. Cambridge University Press, 2000.

Meeusen, W., and J. van den Broeck. Efficiency estimation from Cobb-Douglas production functions with composed error. International Economic Review 18(1977): 435-444.

Ritter, C., and L. Simar. Pitfalls of Normal-Gamma Stochastic Frontier Models. Journal of Productivity Analysis 8(1997): 167-182.

Schultz, T.W. Transforming Traditional Agriculture. Yale Univ. Press, New Haven, CT. USA, 1964.

Sharif, N. R. and A.A. Dar. An Empirical Study of the Patterns and Sources of Technical Inefficiency in Traditional and HYV Rice Cultivation in Bangladesh. Journal of Development Studies 32(1996): 612-629.

Sherlund, S.M, C.B. Barrett, and A.A. Adesina. Smallholder technical efficiency controlling for environmental production conditions. Journal of Development Economics 69(2002): 85-101.

Walker, T. S. and Ryan, J. G. Village and Household Economies in India's. Semi-arid Tropics. Johns Hopkins University Press, Baltimore, MD, 1990. 
Table 1. Composition of nutrients across toposequence-defined land types

\begin{tabular}{|l|c|c|c|c|c|}
\hline Land type & $\begin{array}{c}\text { Number } \\
\text { of samples }\end{array}$ & $\begin{array}{c}\text { Org. C } \\
(\%)\end{array}$ & $\begin{array}{c}\text { Ave. P } \\
(\mathrm{kg} / \mathrm{ha})\end{array}$ & $\begin{array}{c}\text { Ave. K } \\
(\mathrm{kg} / \mathrm{ha})\end{array}$ & $\begin{array}{c}\text { Total } \\
\mathrm{N}(\%)\end{array}$ \\
\hline Upland & 3 & 0.38 & 12 & 84 & 0.03 \\
\hline Mid-upland & 6 & 0.53 & 18 & 82 & 0.05 \\
\hline Medium land & 6 & 0.56 & 21 & 267 & 0.05 \\
\hline Lowland & 21 & 0.77 & 24 & 185 & 0.07 \\
\hline
\end{tabular}

Notes: C-Carbon, P-Potassium, K-Phosphorous, and N-Nitrogen.

Source: Soil chemical analysis conducted at Indian Statistical Institute, Kolkata, India.

Table 2. Summary statistics for variables used in SFPF estimates

\begin{tabular}{|c|c|c|c|c|}
\hline $\begin{array}{l}\text { Sample/Sub-Sample (sample size) } \\
\text { Variable } \\
\end{array}$ & $\begin{array}{l}\text { Sample } \\
\text { Mean }\end{array}$ & $\begin{array}{l}\text { Coefficient } \\
\text { of Variation }\end{array}$ & $\begin{array}{l}\text { Minimum } \\
\text { Value }\end{array}$ & $\begin{array}{l}\text { Maximum } \\
\text { Value }\end{array}$ \\
\hline \multicolumn{5}{|c|}{ All Kharif season rice plots planted with modern varieties $(\mathrm{N}=169)$} \\
\hline yield (kg./ha.) & $1,044.3$ & 6.179 & 45.0 & $8,420.0$ \\
\hline land (ha.) & 0.892 & 0.005 & 0.05 & 12.16 \\
\hline seed (kg.) & 42.50 & 0.251 & 2.00 & 550.00 \\
\hline fertilizer (100 kg.) & 2.803 & 0.017 & 0.000 & 19.800 \\
\hline labor (person-days) & 65.78 & 0.389 & 6.00 & 368.00 \\
\hline upland land-type plot $(0 / 1)$ & 0.036 & -- & 0 & 1 \\
\hline mid-upland plot $(0 / 1)$ & 0.284 & -- & 0 & 1 \\
\hline medium land plot $(0 / 1)$ & 0.254 & -- & 0 & 1 \\
\hline lowland plot $(0 / 1)$ & 0.426 & -- & 0 & 1 \\
\hline irrigation available $(0 / 1)$ & 0.090 & -- & 0 & 1 \\
\hline \multicolumn{5}{|c|}{ All Kharif season rice plots planted with traditional varieties $(\mathrm{N}=920)$} \\
\hline yield (kg./ha.) & 907.6 & 1.174 & 30.0 & $12,592.0$ \\
\hline land (ha.) & 0.940 & 1.055 & 0.025 & 10.47 \\
\hline seed (kg.) & 48.619 & 1.131 & 1.00 & 525.00 \\
\hline fertilizer (kg.) & 2.260 & 1.343 & 0.000 & 36.000 \\
\hline labor (person-days) & 74.484 & 0.986 & 3.00 & 823.00 \\
\hline upland land-type plot $(0 / 1)$ & 0.114 & -- & 0 & 1 \\
\hline mid-upland plot $(0 / 1)$ & 0.485 & -- & 0 & 1 \\
\hline medium land plot $(0 / 1)$ & 0.140 & -- & 0 & 1 \\
\hline lowland plot $(0 / 1)$ & 0.260 & -- & 0 & 1 \\
\hline irrigation available $(0 / 1)$ & 0.090 & -- & 0 & 1 \\
\hline
\end{tabular}

(Table continues...) 
Table 2. Summary statistics for variables used in SFPF estimates (concluded)

\begin{tabular}{ccccc}
\hline Sample/Sub-Sample (sample size) & $\begin{array}{c}\text { Sample } \\
\text { Mean }\end{array}$ & $\begin{array}{l}\text { Coefficient } \\
\text { of Variation }\end{array}$ & $\begin{array}{c}\text { Minimum } \\
\text { Value }\end{array}$ & $\begin{array}{c}\text { Maximum } \\
\text { Value }\end{array}$ \\
\hline Vharif season traditional variety rice plots on upland $(\mathrm{N}=105)$ & & & \\
yield (kg./ha.) & 471.3 & 4.489 & 40.0 & $1,645.0$ \\
land (ha.) & 0.726 & 0.007 & 0.030 & 4.000 \\
seed (kg.) & 36.34 & 0.346 & 2.00 & 140.00 \\
fertilizer (kg.) & 0.966 & 0.009 & 0.000 & 8.680 \\
labor (person-days) & 47.38 & 0.451 & 3.00 & 267.00 \\
irrigation available (0/1) & 0.048 & -- & 0 & 1 \\
Kharif season traditional variety rice plots on middle upland (N=446) & & \\
yield (kg./ha.) & 848.0 & 1.901 & 30.0 & $7,350.0$ \\
land (ha.) & 0.972 & 0.002 & 0.025 & 9.000 \\
seed (kg.) & 50.128 & 0.112 & 1.00 & 420.00 \\
fertilizer (kg.) & 2.350 & 0.005 & 0.000 & 36.000 \\
labor (person-days) & 77.910 & 0.175 & 3.50 & 823.00 \\
irrigation available (0/1) & 0.100 & -- & 0 & 1 \\
Kharif season traditional variety rice plots on medium land $(\mathrm{N}=129)$ & & \\
yield (kg./ha.) & $1,019.5$ & 7.903 & 90.0 & $7,140.0$ \\
land (ha.) & 0.928 & 0.007 & 0.060 & 6.000 \\
seed (kg.) & 46.257 & 0.359 & 2.75 & 525.00 \\
fertilizer (kg.) & 2.473 & 0.019 & 0.000 & 27.000 \\
labor (person-days) & 77.054 & 0.597 & 6.00 & 430.00 \\
irrigation available (0/1) & 0.147 & -- & 0 & 1 \\
Kharif season traditional variety rice plots on medium land $(\mathrm{N}=239)$ & & \\
yield (kg./ha.) & $1,148.9$ & 1.263 & 35.0 & $12,592.0$ \\
land (ha.) & 0.977 & 1.162 & 0.030 & 10.470 \\
seed (kg.) & 52.335 & 1.138 & 2.00 & 490.00 \\
fertilizer (kg.) & 2.546 & 1.223 & 0.000 & 20.000 \\
labor (person-days) & 78.192 & 0.961 & 3.50 & 498.00 \\
irrigation available (0/1) & 0.059 & -- & 0 & 1 \\
\hline
\end{tabular}


Table 3. Input elasticities and standard deviation from SFPF estimates (based on the MINIMUM model with production inputs only)

\begin{tabular}{|c|c|c|c|c|c|c|c|}
\hline & \multicolumn{7}{|c|}{ Alternative plot/land-type disaggregation levels } \\
\hline & \multirow[b]{2}{*}{ Farm level } & \multicolumn{2}{|c|}{ Plots pooled by land-type: } & \multicolumn{4}{|c|}{ Plot specific estimates: } \\
\hline & & $\begin{array}{c}\text { Modern } \\
\text { Varieties } \\
\text { (MV) only }\end{array}$ & $\begin{array}{c}\text { Traditional } \\
\text { Varieties } \\
\text { (TV) only }\end{array}$ & $\begin{array}{l}\text { upland } \\
\text { (TV only) }\end{array}$ & $\begin{array}{l}\text { mid-upland } \\
\text { (TV only) }\end{array}$ & $\begin{array}{l}\text { medium } \\
\text { land } \\
\text { (TV only) }\end{array}$ & $\begin{array}{l}\text { lowland } \\
\text { (TV only) }\end{array}$ \\
\hline \multicolumn{8}{|c|}{ Production input: } \\
\hline Land & $\begin{array}{l}0.7088 \\
(0.134) \\
\end{array}$ & $\begin{array}{l}0.4728 \\
(0.211) \\
\end{array}$ & $\begin{array}{l}0.5787 \\
(0.183) \\
\end{array}$ & $\begin{array}{l}0.2195 \\
(0.260) \\
\end{array}$ & $\begin{array}{c}0.5782 \\
(0.170) \\
\end{array}$ & $\begin{array}{l}0.8690 \\
(0.046) \\
\end{array}$ & $\begin{array}{l}0.6363 \\
(0.156) \\
\end{array}$ \\
\hline Fertilizer & $\begin{array}{l}0.0436 \\
(0.025)\end{array}$ & $\begin{array}{l}0.0646 \\
(0.054)\end{array}$ & $\begin{array}{l}0.0565 \\
(0.032)\end{array}$ & $\begin{array}{l}0.0749 \\
(0.174)\end{array}$ & $\begin{array}{l}0.0648 \\
(0.046)\end{array}$ & $\begin{array}{l}0.0069 \\
(0.012)\end{array}$ & $\begin{array}{l}0.0160 \\
(0.034)\end{array}$ \\
\hline Labor & $\begin{array}{c}-0.0521 \\
(0.042) \\
\end{array}$ & $\begin{array}{l}0.0155 \\
(0.114) \\
\end{array}$ & $\begin{array}{l}0.0702 \\
(0.100) \\
\end{array}$ & $\begin{array}{l}0.1182 \\
(0.182) \\
\end{array}$ & $\begin{array}{l}0.0379 \\
(0.075) \\
\end{array}$ & $\begin{array}{c}-0.0092 \\
(0.042) \\
\end{array}$ & $\begin{array}{l}0.0889 \\
(0.094) \\
\end{array}$ \\
\hline Seed & $\begin{array}{l}0.2646 \\
(0.095) \\
\end{array}$ & $\begin{array}{l}0.3703 \\
(0.065) \\
\end{array}$ & $\begin{array}{l}0.2580 \\
(0.105) \\
\end{array}$ & $\begin{array}{l}0.4075 \\
(0.228) \\
\end{array}$ & $\begin{array}{l}0.2726 \\
(0.178) \\
\end{array}$ & $\begin{array}{l}0.0841 \\
(0.035) \\
\end{array}$ & $\begin{array}{l}0.2320 \\
(0.143) \\
\end{array}$ \\
\hline
\end{tabular}

Table 4. Input elasticities and standard deviation from SFPF estimates (based on the FULL model with irrigation and village controls)

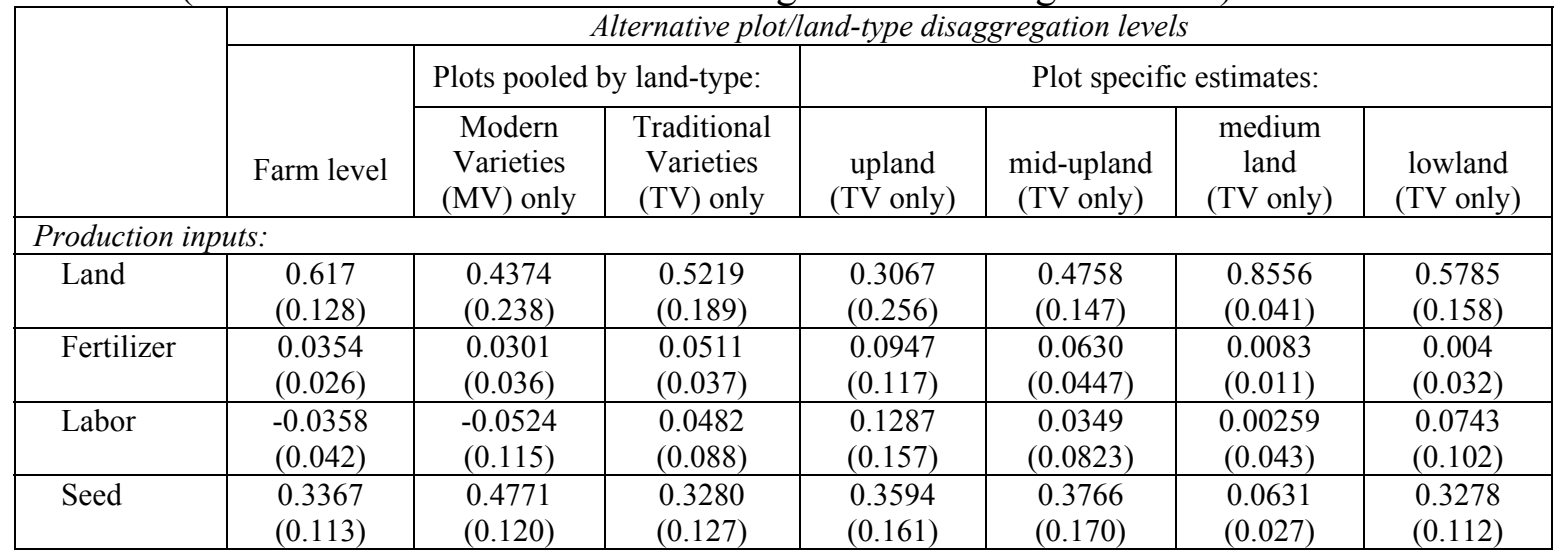


Table 5. Estimates of farm technical efficiency in rice cultivation: Model variants

Mixture Wald chi-square test statistics $\left(\mathrm{h}_{0}: \sigma_{\mathrm{u}}=0\right)$ for the presence of technical inefficiency (p-value in parentheses) and estimated $\lambda=\sigma_{u} / \sigma_{v}(95 \%$ confidence interval in square bracket)

\begin{tabular}{|c|c|c|c|c|c|c|c|}
\hline & \multicolumn{7}{|c|}{ Alternative plot/land-type disaggregation levels } \\
\hline & & \multicolumn{2}{|c|}{ Plots pooled by land-type: } & \multicolumn{4}{|c|}{ Plot specific estimates: } \\
\hline & Farm level & $\begin{array}{c}\text { Modern } \\
\text { Varieties } \\
\text { (MV) only }\end{array}$ & $\begin{array}{l}\text { Traditional } \\
\text { Varieties } \\
\text { (TV) only }\end{array}$ & $\begin{array}{c}\text { upland } \\
\text { (TV only) }\end{array}$ & $\begin{array}{l}\text { mid-upland } \\
\text { (TV only) }\end{array}$ & $\begin{array}{l}\text { medium } \\
\text { land } \\
\text { (TV only) }\end{array}$ & $\begin{array}{l}\text { lowland } \\
\text { (TV only) }\end{array}$ \\
\hline sample size & 469 & 169 & 920 & 105 & 446 & 129 & 239 \\
\hline $\begin{array}{l}\text { functional } \\
\text { form }\end{array}$ & Translog & Translog & Translog & Translog & Translog & $\begin{array}{c}\text { Cobb- } \\
\text { Douglas }\end{array}$ & Translog \\
\hline \multicolumn{8}{|c|}{ alternative specifications for the production frontier: } \\
\hline $\begin{array}{l}\text { Minimum } \\
\text { (land, seed, } \\
\text { fertilizer, } \\
\text { labor only) }\end{array}$ & $\begin{array}{c}21.54 \\
(0.00) \\
\lambda=1.844 \\
{[1.748} \\
-1.940]\end{array}$ & $\begin{array}{c}0.00 \\
(1.00) \\
\lambda=0.0158 \\
{[-0.4618} \\
-0.4934]\end{array}$ & $\begin{array}{c}-13.58 \\
(0.00) \\
\lambda=1.402 \\
{[1.2996} \\
-1.505]\end{array}$ & $\begin{array}{c}4.93 \\
(0.013) \\
\lambda=2.383 \\
{[2.156} \\
-2.610]\end{array}$ & $\begin{array}{c}4.06 \\
(0.022) \\
\lambda=1.149 \\
{[1.014} \\
-1.284]\end{array}$ & $\begin{array}{c}3.68 \\
(0.027) \\
\lambda=1.373 \\
{[1.234} \\
-1.512]\end{array}$ & $\begin{array}{c}17.76 \\
(0.00) \\
\lambda=2.3601 \\
{[2.247} \\
-2.473]\end{array}$ \\
\hline $\begin{array}{l}\text { + land type } \\
\text { dummy (or } \\
\text { land type } \\
\text { shares) }\end{array}$ & $\begin{array}{c}16.08 \\
(0.00) \\
\lambda=1.591 \\
{[1.502} \\
-1.680]\end{array}$ & $\begin{array}{c}0.00 \\
(1.00) \\
\lambda=0.0107 \\
{[-0.5288} \\
-0.5502]\end{array}$ & $\begin{array}{c}18.79 \\
(0.00) \\
\lambda=1.458 \\
{[1.3756} \\
-1.5397]\end{array}$ & ---- & ----- & ----- & ----- \\
\hline $\begin{array}{l}\text { +landtype } \\
\text { +irrigation/ } \\
\text { \& village } \\
\text { dummy }\end{array}$ & ----- & $\begin{array}{c}0.00 \\
(1.00) \\
\lambda=0.0238 \\
{[-0.2297} \\
-0.2774]\end{array}$ & $\begin{array}{c}9.14 \\
(0.001) \\
\lambda=1.2716 \\
{[1.171} \\
-1.372] \\
\end{array}$ & ----- & ----- & ----- & ----- \\
\hline $\begin{array}{l}\text { +irrigation/ } \\
\& \text { village } \\
\text { dummy }\end{array}$ & $\begin{array}{c}8.94 \\
(0.001) \\
\lambda=1.420 \\
{[1.319} \\
-1.521]\end{array}$ & ----- & ----- & $\begin{array}{c}0.00 \\
(1.00) \\
\lambda=0.0401 \\
{[-1.001} \\
-0.081] \\
\end{array}$ & $\begin{array}{c}0.00 \\
(1.00) \\
\lambda=0.0150 \\
{[-0.408} \\
-0.438]\end{array}$ & $\begin{array}{c}12.79 \\
(0.00) \\
\lambda=3.391 \\
{[3.265} \\
-3.517]\end{array}$ & $\begin{array}{c}10.59 \\
(0.001) \\
\lambda=2.501 \\
{[2.3386} \\
-2.6631]\end{array}$ \\
\hline
\end{tabular}


Table 6. Mean predicted technical efficiency scores (observation range in square bracket)

\begin{tabular}{|c|c|c|c|c|c|c|c|}
\hline & \multicolumn{7}{|c|}{ Alternative plot/land-type disaggregation levels } \\
\hline & \multirow[b]{2}{*}{ Farm level } & \multicolumn{2}{|c|}{ Plots pooled by land-type: } & \multicolumn{4}{|c|}{ Plot specific estimates: } \\
\hline & & $\begin{array}{c}\text { Modern } \\
\text { Varieties } \\
\text { (MV) only } \\
\end{array}$ & $\begin{array}{l}\text { Traditional } \\
\text { Varieties } \\
\text { (TV) only }\end{array}$ & $\begin{array}{c}\text { upland } \\
\text { (TV only) }\end{array}$ & $\begin{array}{l}\text { mid-upland } \\
\text { (TV only) }\end{array}$ & $\begin{array}{l}\text { medium } \\
\text { land } \\
\text { (TV only) }\end{array}$ & $\begin{array}{l}\text { lowland } \\
\text { (TV only) }\end{array}$ \\
\hline \multicolumn{8}{|c|}{ alternative specifications: } \\
\hline $\begin{array}{l}\text { Minimum } \\
\text { (land, seed, } \\
\text { fertilizer, } \\
\text { labor only) }\end{array}$ & $\begin{array}{c}0.7544 \\
{[0.2368} \\
-0.9506]\end{array}$ & $\begin{array}{c}0.9955 \\
{[0.9954} \\
-0.9956]\end{array}$ & $\begin{array}{c}0.7531 \\
{[0.3332-} \\
0.9421]\end{array}$ & $\begin{array}{c}0.7015 \\
{[0.2862} \\
-0.9293]\end{array}$ & $\begin{array}{c}0.8010 \\
{[0.4293} \\
-0.9542]\end{array}$ & $\begin{array}{c}0.8255 \\
{[0.4654} \\
-0.9580]\end{array}$ & $\begin{array}{c}0.7196 \\
{[0.2265} \\
-0.9561]\end{array}$ \\
\hline $\begin{array}{l}\text { + land type } \\
\text { dummy (or } \\
\text { land type } \\
\text { shares) }\end{array}$ & $\begin{array}{c}0.7844 \\
{[0.3271} \\
-0.9510]\end{array}$ & ----- & ----- & ----- & ----- & ----- & ----- \\
\hline $\begin{array}{l}\text { +landtype } \\
\text { +irrigation } \\
\text { \& village } \\
\text { dummy }\end{array}$ & ----- & $\begin{array}{c}0.9940 \\
{[0.9938} \\
-0.9944]\end{array}$ & $\begin{array}{c}0.7877 \\
{[0.4084-} \\
0.9576]\end{array}$ & ----- & ----- & ----- & ----- \\
\hline $\begin{array}{l}\text { +irrigation \& } \\
\text { village } \\
\text { dummy }\end{array}$ & $\begin{array}{c}0.8029 \\
{[0.3969} \\
-0.9544]\end{array}$ & ----- & ----- & $\begin{array}{c}0.9898 \\
{[0.9894} \\
-0.9903]\end{array}$ & $\begin{array}{c}0.9965 \\
{[0.9964} \\
-0.9966]\end{array}$ & $\begin{array}{c}0.7860 \\
{[0.2981} \\
-0.9596]\end{array}$ & $\begin{array}{c}0.7240 \\
{[0.2737} \\
-0.9520]\end{array}$ \\
\hline
\end{tabular}

